\title{
Perspectives on creating clinically relevant blast models for mild traumatic brain injury and post traumatic stress disorder symptoms
}

\author{
Lisa A. Brenner ${ }^{1,2,3,4}$ *, Nazanin Bahraini ${ }^{1,2}$ and Theresa D. Hernández ${ }^{1,5}$ \\ 1 Veterans Integrated Service Network 19, Mental IIIness Research Education and Clinical Center, Denver, CO, USA \\ ${ }^{2}$ Department of Psychiatry, School of Medicine, University of Colorado, Denver, Aurora, CO, USA \\ ${ }^{3}$ Department of Neurology, School of Medicine, University of Colorado, Denver, Aurora, CO, USA \\ ${ }^{4}$ Department of Physical Medicine and Rehabilitation, School of Medicine, University of Colorado, Denver, Aurora, CO, USA \\ ${ }^{5}$ Department of Psychology and Neuroscience, University of Colorado, Boulder, CO, USA
}

Edited by:

Ibolja Cernak, Johns Hopkins

University Applied Physics Lab, USA

Reviewed by:

Luke R. Johnson, Uniformed Services University of the Health Sciences,

USA

Bridgette D. Semple, University of California San Francisco, USA

*Correspondence:

Lisa A. Brenner, Veterans Integrated Service Network 19, Mental IIIness

Research Education and Clinical Center, VISN 19 MIRECC, Denver

VAMC, 1055 Clermont Street, Denver, CO 80220, USA.

e-mail: lisa.brenner@va.gov
Military personnel are returning from Iraq and Afghanistan and reporting non-specific physical (somatic), behavioral, psychological, and cognitive symptoms. Many of these symptoms are frequently associated with mild traumatic brain injury (mTBI) and/or post traumatic stress disorder (PTSD). Despite significant attention and advances in assessment and intervention for these two conditions, challenges persist. To address this, clinically relevant blast models are essential in the full characterization of this type of injury, as well as in the testing and identification of potential treatment strategies. In this publication, existing diagnostic challenges and current treatment practices for mTBI and/or PTSD will be summarized, along with suggestions regarding how what has been learned from existing models of PTSD and traditional mechanism (e.g., non-blast) traumatic brain injury can be used to facilitate the development of clinically relevant blast models.

Keywords: blast, traumatic brain injury, post traumatic stress disorder, animal models, human

\section{INTRODUCTION}

Findings suggest that explosive mechanisms (e.g., improvised explosive devices [IEDs], rocket-propelled grenades [RPGs]) account for $56-78 \%$ of injuries being sustained by military personnel serving in Iraq and Afghanistan (Owens et al., 2008; Sayer et al., 2008). Following exposure, individuals are reporting a range of non-specific physical, psychological, and behavioral symptoms including headaches, decreased sleep, fatigue, depressed and anxious mood, and problems with concentration and memory. For many, symptoms are also accompanied by decreased psychosocial functioning (e.g., poor work performance, increased conflicts with significant others). Clinical presentation following exposure to blast is heterogeneous, and appears to be dependent on a widerange of contextual factors (e.g., proximity to the blast, whether or not the individual sustained other injuries). Pre-existing individual differences (e.g., history of childhood trauma, social support) further contribute to variations in presentation. Unfortunately, these individual and contextual factors are not alone in contributing to diagnostic and treatment challenges. Wide-ranging limitations in existing knowledge - such as the physiological impact of blast exposure on humans, and means of objectively assessing history of mild traumatic brain injury (mTBI; Brenner et al., 2009; Brenner, 2011) - further impede effective assessment and intervention.

Nevertheless, based on evidence from the acute and post-acute clinical presentation of military personnel returning from battle and animal models (Cernak et al., 2011; Koliatsos et al., 2011) existing efforts have focused on two conditions, mTBI and post traumatic stress disorder (PTSD). This is in part related to the rates of these conditions being reported in returning military personnel. The percent of individuals among specified military cohorts reporting a history of mTBI varies widely $(8-23 \%)$ and appears to be dependent upon multiple factors (e.g., time served, combat exposure, Military Occupational Specialty [MOS; Vasterling et al., 2006; Terrio et al., 2009]). Data also suggests that among those with a military-related mTBI the rate of symptoms associated with the injury reported decreases over time (Terrio et al., 2009). Rates of PTSD appear to also vary. Findings from a populationbased study of previously deployed OEF/OIF military personnel suggested that the prevalence rate of PTSD was $13.8 \%$ (Tanielian and Jaycox, 2008). Recent work by the Armed Forces Health Surveillance Center (2011) suggested that in every gender, age, and MOS subgroup, larger percentages of those who deployed were diagnosed with PTSD and anxiety-related disorders after the second and/or third deployment versus the first. Using Department of Veterans Affairs administrative data, Maguen et al. (2010) found that $17 \%$ of female and $22 \%$ of male OEF/OIF Veterans seeking VA health care were diagnosed with PTSD. The goal of this publication is to briefly summarize existing diagnostic challenges and current treatment practices for mTBI and/or PTSD, with the aim of highlighting the importance of creating clinically relevant blast models. Commentary on how existing work in the areas of PTSD and traditional mechanism (e.g., non-blast) traumatic brain injury (TBI) can be used to facilitate such development is also provided. 


\section{MILD TBI AND PTSD: DIAGNOSTIC CRITERIA}

To meet diagnostic criteria for TBI one must have experienced an event (e.g., blast exposure, motor vehicle accident) which results in a structural injury to the brain or a physiological disruption of brain function (alteration of consciousness [AOC], loss of consciousness [LOC]). Severity of TBI is classified according to the extent of injury to the brain or altered consciousness post-injury, versus sequelae reported or observed post-exposure. According to the American Congress of Rehabilitation Medicine to meet diagnostic criteria for mTBI one must have had a traumatically induced physiological disruption of brain function as manifested by at least one of the following: (1) any period of LOC; (2) any loss of memory for events immediately before or after the injury; (3) any alteration in mental state at the time of the injury (e.g., feeling dazed, disoriented, and confused); and/or (4) focal neurological deficits that may or may not be transient (Kay et al., 1993). At the same time, the following must not be exceeded: (1) LOC of $30 \mathrm{~min}$; (2) after $30 \mathrm{~min}$, Glasgow Coma Scale score of 13-15; and/or (3) post traumatic amnesia (PTA) of $24 \mathrm{~h}$ (Kay et al., 1993).

Similarly, to meet criteria for PTSD an individual must be exposed to a traumatic event, however, in this case the nature of the "injury" is psychological versus physiological. Moreover, the diagnosis of PTSD is based on the emergence of persistent symptoms which cause significant distress and impact functioning over time. The Diagnostic and Statistic Manual of Mental DisordersIV (DSM-IV; American Psychiatric Association, 2000) defines a "traumatic event" as one in which "(1) the person experienced, witnessed, or was confronted with an event or events that involved actual or threatened death or serious injury, or a threat to the physical integrity of self or others; and (2) the person's response involved intense fear, helplessness, or horror" (p. 427-428). PTSD symptoms are clustered into three categories including re-experiencing of the traumatic event, avoidance of trauma-related stimuli and/or emotional numbing, and hyperarousal.

\section{MILD TBI AND PTSD: SYMPTOMS}

The constellation of symptoms present after blast-induced mTBI, often called post-concussive symptoms (PCS), are similar to those reported by individuals with traditional mechanism TBI and include physical (somatic), behavioral, psychological, and cognitive complaints (i.e., headaches, balance problems, dizziness, fatigue, irritability, and poor memory and concentration; Terrio et al., 2009). Further discussion of cognitive-related symptoms is available in recently published articles (Sayer et al., 2008; Belanger et al., 2009, 2011; Lippa et al., 2010). Although data from civilian traditional mechanism mTBI populations suggest that most individuals return baseline functioning within a year (Alexander, 1995), for some PCS persist and lead to decreased psychosocial functioning (Belanger et al., 2005). As with other types of TBI, PCS following blast-induced TBI may be staggered in their onset, fluctuate in severity, and be triggered by life stressors months after injury (Hicks et al., 2010). The underlying causes and mechanisms of these symptoms are likely multi-factorial (e.g., neurological changes in the brain, damage to sensory organs, and stress responses). That is, the extent to which blast-induced neurological changes account for these symptoms is unclear. While some studies have found greater symptom complaints in those with more severe injuries (McLean et al., 1993; Masson et al., 1996) the severity of blast exposure necessary to cause persistent symptoms has not been clearly identified (Hicks et al., 2010). Likewise, comprehensive investigation into the effects of repeated blast exposure has yet to be conducted; though it has been shown that recovery from PCS occurs more slowly with repeated TBIs (Hicks et al., 2010).

While discerning a reliable and distinct profile for blast-induced TBI is complicated, one distinct feature of blast-induced TBI emerging in the literature is the presence of auditory complications, namely hearing loss and tinnitus (Lew et al., 2007; Belanger et al., 2011). A study by Belanger et al. (2011) showed that the only PCS symptom to differentiate between those sustaining a blastinduced mTBI and those who had a non-blast induced mTBI was hearing difficulties. Similarly, Wilk et al. (2010) found higher levels of headache and tinnitus, in those with blast mTBI compared to those without a blast-related injury.

An increased incidence of PTSD symptoms has also been noted following blast exposure (Hoge et al., 2008; Belanger et al., 2009). Although PTSD symptoms are clustered into specific three categories, individual expression of these symptoms varies. Whereas one Veteran may only re-experience traumatic combat experiences while asleep, another may report flashbacks being triggered by sounds and smells encountered at work or school. Moreover, returning military personnel with PTSD are also endorsing cognitive and somatic complaints (Hoge et al., 2007; Brenner et al., 2010). Given the significant overlap in the diagnostic features of PTSD with PCS, it can be challenging to differentiate between symptoms caused by severe stress and/or mild TBI. Symptom attribution can made even more difficult when relying on retrospective accounts of injury events (Hicks et al., 2010; Belanger et al., 2011). That is, clinicians working with returning military personnel are often attempting to piece together histories from events which occurred months to years prior.

\section{TBI AND PTSD: EMERGING EVIDENCED REGARDING CO-OCCURRENCE}

Presentation of symptoms following blast-induced TBI is frequently complicated by co-morbid psychiatric conditions, such as PTSD. There is a likelihood that affective symptoms associated with PTSD will interact with the PCS and other physical symptomatology to potentially worsen outcomes. For example, Brenner et al. (2010) found that in Soldiers with histories of physical injury, mTBI, and PTSD were independently associated with PCS. Moreover, a combination of the conditions was found to be more strongly associated with PCS than either condition alone. Emerging research also suggests that a history of TBI increases risk for developing PTSD. Bryant et al. (2010) hypothesize that damage to the frontal regions of the brain may compromise neural networks which are required to regulate emotional experiences and as such predispose such patients to increased anxiety and depression (Bryant et al., 2010).

\section{CURRENT TREATMENTS \\ TRAUMATIC BRAIN INJURY}

There is great need for effective TBI interventions across all severities - perhaps even more so for mTBI given its prevalence. Unfortunately, clinically tested neuroprotective therapies 
in moderate-severe TBI have been disappointing, even after preclinical investigation in animal models (Margulies and Hicks, 2009). As well, the rigor of available studies of symptom-targeted therapies during post-acute TBI, even in mild cases, does not allow for the development of definitive treatment standards (Warden et al., 2006). That said, a few avenues look promising. First, the importance of combination therapies is a new driving force in the development of pharmacological interventions for complicated mild to severe TBI, including the statins (Margulies and Hicks, 2009) and citicoline (Zafonte et al., 2009). Second, progesterone is the only pharmacotherapy that has thus far emerged successfully from animal model to clinical trial (Sayeed and Stein, 2009) with early signs of the drug being safe and likely beneficial in the acute post-TBI period among those with moderate to severe injuries (Wright et al., 2007). A multi-center, placebo controlled Phase III trial of progesterone is ongoing. Third, non-pharmacological interventions have also been found to improve outcomes. This was seen following telephone intervention trials in mild to severe TBI, in which the intervention was associated with improved overall function, functional status, quality of life, and depression measures in comparison to a control group with standard follow-up (Bell et al., 2005, 2008; Bombardier et al., 2009). Functional benefits were also reported in a placebo controlled trial of acupressure in post-acute mild TBI (McFadden et al., 2010).

\section{PSYCHOSOCIAL INTERVENTIONS FOR PTSD}

In the past two decades there have been substantial advances in the development of evidence-based psychological treatments for PTSD. Components of effective PTSD treatments include an element of exposure and/or cognitive restructuring. Variants of exposure therapy, including prolonged-exposure therapy (PE; Foa et al., 2007) have received the most empirical evidence for their efficacy in treating PTSD. The overall aim of PE is to help trauma survivors emotionally process their traumatic experiences in order to reduce PTSD and other trauma-related symptoms (Foa et al., 2007). This is accomplished through repeated exposure (imaginal and/or in vivo) to the traumatic memory, which results in habituation of the fear response, allowing the individual to process the trauma memory and regain mastery of their thoughts and feelings around the incident.

Cognitive-processing therapy (CPT; Resick et al., 2010), a form of cognitive behavioral therapy, has also been shown to be highly efficacious in treating PTSD. CPT is based on social cognitive theory which is focused more on the content of cognitions and the effect that distorted thoughts may have on emotional responses (Resick et al., 2010). In this vein, CPT through the use of various cognitive strategies, helps individuals alter distorted or maladaptive beliefs related to the traumatic event, which then creates a change in the emotional response associated with the trauma.

\section{PSYCHOPHARMACOLOGICAL TREATMENT FOR PTSD}

Empirical research on effective pharmacotherapy for PTSD has produced mixed findings. This is in part due to the fact that clinical presentation in PTSD is quite variable and individuals with PTSD often present with other psychiatric co-morbidities. Despite these complexities, advances in neurobiology have shed some light on the relevant neurobiological systems implicated in PTSD, which has prompted the investigation of pharmacological agents to target these systems in order to alleviate PTSD symptoms (Albucher and Liberzon, 2002; Friedman and Davidson, 2007). The body of evidence on pharmacological treatment of PTSD suggests that antidepressants demonstrate the best overall efficacy for the treatment of PTSD (Albucher and Liberzon, 2002). Of the various classes of antidepressants, selective serotonin reuptake inhibitors (SSRIs) compared to tricyclic antidepressants (TCAs) and monoamine oxidase inhibitors (MAOIs) appear to be the treatment of choice for PTSD (Albucher and Liberzon, 2002; American Psychiatric Association Steering Committee on Practice Guidelines, 2004; Management of Post-Traumatic Stress Working Group, 2010). This is largely due to their demonstrated efficacy across several large controlled trials, their greater ease of use, lower risk of overdose, and fewer side effects (Albucher and Liberzon, 2002). Other medications, such as mood stabilizers, atypical neuroleptics, and newer antidepressants also show promise; however, further controlled trials are needed to clarify their efficacy for specific PTSD symptoms (Albucher and Liberzon, 2002; Friedman and Davidson, 2007).

\section{TBI AND PTSD}

While there are effective treatments for PTSD and some potentially on the horizon for mTBI, there is unfortunately a dearth of evidence-based treatments for those with these co-morbid conditions (Soo and Tate, 2007). In the interim, expert consensus supports providing those with mTBI plus PTSD the two best evidence-based treatments in the Department of Veterans Affairs and Department of Defense practice guidelines for PTSD, PE, or CPT (National Center for Posttraumatic Stress Disorder, 2010).

\section{CLINICAL REALITIES AND BLAST MODELING MODELING OF TRADITIONAL MECHANISM TBI: CHALLENGES AND LESSONS LEARNED}

Developing animal models of TBI poses many challenges. Animal studies often involve injury to only the brain, in precise regions and without co-occurring physical insult to the periphery or psychological trauma. As such, the contribution of these additional factors to the "clinical picture" of the animal following injury (e.g., functional deficits and recovery) cannot be accurately accounted for. From the other direction, it is possible to statistically control for some of these variables (e.g., injury severity, age) in clinical studies, but this still may not reduce the clinical case to that of an animal model. Still in its early stages, blast-associated injury models range from those accounting for mechanisms of injury using isolated spinal cord (Connell et al., 2011), to injury dosing in cell cultures (Arun et al., 2011) to rodent models in which lethality, pathophysiological markers of injury and functional deficits can be measured (Kuehn et al., 2011). The development of blast injury models can benefit from the many preceding decades in which the study of animal models of non-blast TBI has been fine-tuned to include multiple behavioral measures of post-injury sequelae and functional change over time, as well as the pathophysiological markers associated with this temporal pattern.

\section{MODELING OF PTSD: CHALLENGES AND LESSONS LEARNED}

The complexity of PTSD, in terms of its symptoms and comorbidities would not appear to easily lend itself to being studied in an animal model. However, because PTSD symptoms are fairly 
well-characterized, it has been possible to model certain aspects or phenotypes of the disorder (Jovanovic and Norrholm, 2011; Skelton et al., 2012). A good example of this is inhibition of fear (or learning of safety signals), which has been extensively studied in multiple species. Neurocircuitry has been elucidated in rodents which appears to model the human condition. Moreover, when the animal model protocol is tested in clinical populations it distinguishes between PTSD and depression (Jovanovic et al., 2010). This successful translation of an animal model (fear potentiated startle and inhibition of fear potentiated startle) to clinical study (fear potentiated startle and fear inhibition), as well as the ongoing research discourse between these is a welcome rarity. What has yet to be developed, however, is a model that evokes lack of fear inhibition after TBI. Once developed, such a model could also serve as a vehicle for ongoing research discourse between bench and bedside.

\section{GUIDANCE REGARDING FUTURE EFFORTS}

While the research on recovery from TBI within neuroscience may be considered relatively "young," (Rose and Johnson, 1992) there have been enormous strides in the past three decades. Within that time, recurrent themes have emerged including the importance of open and frequent interchange between the research in animal models and that in humans, as well as the warning to eschew the "silver bullet" approach to treatment (Kolb, 1992). From these themes, it has become apparent that clinical translation from bench to bedside is not only important, but essential to effectively understanding and developing treatments for mTBI and/or PTSD.

\section{CONCLUSION}

Although advances are being made with respect to identifying empirically supported assessment and treatment methods for

\section{REFERENCES}

Albucher, R. C., and Liberzon, I. (2002). Psychopharmacological treatment in PTSD: a critical review. J. Psychiatr. Res. 36, 355-367.

Alexander, M. P. (1995). Mild traumatic brain injury: pathophysiology, natural history, and clinical management. Neurology 45, 1253-1260.

American Psychiatric Association. (2000). Diagnostic and Statistical Manual of Mental Disorders DSMIV Text Revision. Washington, DC: American Psychiatric Association.

American Psychiatric Association Steering Committee on Practice Guidelines. (2004). Practice Guideline for the Treatment of Patients with Acute Stress Disorder and Posttraumatic Stress Disorder. Arlington: American Psychiatric Association.

Armed Forces Health Surveillance Center. (2011). Associations between repeated deployments to Iraq (OIF/OND) and Afghanistan (OEF) and post-deployment illnesses and injuries, active component, U.S.
Armed Forces, 2003-2010: mental disorders, by gender, age group, military occupation, and "dwell times" prior to repeat (second through fifth) deployments. MSMR 18, 2-11.

Arun, P., Spadaro, J., John, J., Gharavi, R. B., Bentley, T. B., and Nambiar, M. P. (2011). Studies on blast traumatic brain injury using in-vitro model with shock tube. Neuroreport 22, 379-384.

Belanger, H. G., Curtiss, G., Demery, J. A., Lebowitz, B. K., and Vanderploeg, R. D. (2005). Factors moderating neuropsychological outcomes following mild traumatic brain injury: a meta-analysis. J. Int. Neuropsychol. Soc. 11, 215-227.

Belanger, H. G., Kretzmer, T., YoashGantz, R., Pickett, T., and Tupler, L. A. (2009). Cognitive sequelae of blast-related versus other mechanisms of brain trauma. J. Int. Neuropsychol. Soc. 15, 1-8.

Belanger, H. G., Proctor-Weber, Z., Kretzmer, T., Kim, M., French, L. M., and

mTBI and/or PTSD, clinical needs continue to exceed current knowledge. In terms of assessment, accurate, and feasible means of facilitating differential diagnosis have yet to be identified. The future of intervention research lies in examining both novel interventions and focusing on who benefits from current evidencebased practices and under what circumstances treatments are most effective. Heterogeneity in the clinical presentation of those returning from combat suggests that there is likely no "silver bullet." For some, multi-dimensional and combination assessment and treatment approaches are likely to be necessary. It is also important to note that many returning war Veterans report symptoms often associated with mTBI and/or PTSD, but meet diagnostic criteria for neither. As such, clinicians are being encouraged to treat non-specific symptoms regardless of etiology (Brenner et al., 2009). Based on such practices in the reality of the human condition, animal scientists may want to consider focusing on behavioral assessments that best capture clinical presentation, in order to have a model of symptoms, which can then be the target of treatment strategies. The high number of military personnel being affected by blast injuries provides sufficient clinical cases to allow for parallel study of mTBI and/or PTSD in humans and animals. However, increased collaboration between scientists working with animals and humans is required in order to maximize successful translation of both clinical knowledge to the development of animal models, and findings from animal models to clinical practice.

\section{ACKNOWLEDGMENTS}

This material is the result of work supported by the Veterans Integrated Service Network 19, Mental Illness Research Education and Clinical Center. The contents do not represent the views of the Department of Veterans Affairs or the United States Government.

Vanderploeg, R. D. (2011). Symptom complaints following reports of blast versus non-blast mild TBI: does mechanism of injury matter? Clin. Neuropsychol. 25, 702-715.

Bell, K. R., Hoffman, J. M., Temkin, N. R., Powell, J. M., Fraser, R. T., Esselman, P. C., Barber, J. K., and Dikmen, S. (2008). The effect of telephone counselling on reducing posttraumatic symptoms after mild traumatic brain injury: a randomised trial. J. Neurol. Neurosurg. Psychiatr. 79, 1275-1281.

Bell, K. R., Temkin, N. R., Esselman, P. C., Doctor, J. N., Bombardier, C. H., Fraser, R. T., Hoffman, J. M., Powell, J. M., and Dikmen, S. (2005). The effect of a scheduled telephone intervention on outcome after moderate to severe traumatic brain injury: a randomized trial. Arch. Phys. Med. Rehabil. 86, 851-856.

Bombardier, C. H., Bell, K. R., Temkin, N. R., Fann, J. R., Hoffman, J., and Dikmen, S. (2009). The efficacy of a scheduled telephone intervention for ameliorating depressive symptoms during the first year after traumatic brain injury. J. Head Trauma Rehabil. 24, 230-238.

Brenner, L. A. (2011). Neuropsychological and neuroimaging findings in traumatic brain injury and posttraumatic stress disorder. Dialogues Clin. Neurosci. 13, 311-323.

Brenner, L. A., Ivins, B. J., Schwab, K., Warden, D., Nelson, L. A., Jaffee, M., and Terrio, H. (2010). Traumatic brain injury, posttraumatic stress disorder, and postconcussive symptom reporting among troops returning from Iraq. J. Head Trauma Rehabil. 25, 307-312.

Brenner, L. A., Vanderploeg, R. D., and Terrio, H. (2009). Assessment and diagnosis of mild traumatic brain injury, posttraumatic stress disorder, and other polytrauma conditions: burden of adversity hypothesis. Rehabil. Psychol. 54, 239-246.

Bryant, R. A., O'Donnell, M. L., Creamer, M., Mcfarlane, A. C., Clark, C. R., and Silove, D. (2010). 
The psychiatric sequelae of traumatic injury. Am. J. Psychiatry 167, 312-320.

Cernak, I., Merkle, A. C., Koliatsos, V. E., Bilik, J. M., Luong, Q. T., Mahota, T. M., Xu, L., Slack, N., Windle, D., and Ahmed, F. A. (2011). The pathobiology of blast injuries and blastinduced neurotrauma as identified using a new experimental model of injury in mice. Neurobiol. Dis. 41, 538-551.

Connell, S., Gao, J., Chen, J., and Shi, R. (2011). Novel model to investigate blast injury in the central nervous system. J. Neurotrauma 28 , 1229-1236.

Foa, E. B., Hembree, E. A., and Roghbaum, B. O. (2007). Prolonged Exposure Therapy for PTSDL Emotional Processing of Traumatic Experiences Therapist Guide. New York: Oxford University Press.

Friedman, M. J., and Davidson, J. R. (2007). "Pharmacotherapy for PTSD," in Handbook of PTSD: Science and Practice, eds M. J. Friedman, T. M. Keane, and P. A. Resick (New York: Guilford Press), 376-405.

Hicks, R. R., Fertig, S. J., Desrocher, R. E., Koroshetz, W. J., and Pancrazio, J. J. (2010). Neurological effects of blast injury. J. Trauma 68, 1257-1263.

Hoge, C. W., Mcgurk, D., Thomas, J. L., Cox, A. L., Engel, C. C., and Castro, C. A. (2008). Mild traumatic brain injury in U.S. Soldiers returning from Iraq. N. Engl. J. Med. 358, 453-463.

Hoge, C. W., Terhakopian, A., Castro, C. A., Messer, S. C., and Engel, C. C. (2007). Association of posttraumatic stress disorder with somatic symptoms, health care visits, and absenteeism among Iraq war veterans. Am. J. Psychiatry 164, 150-153.

Jovanovic, T., and Norrholm, S. D. (2011). Neural mechanisms of impaired fear inhibition in posttraumatic stress disorder. Front. Behav. Neurosci. 5:44. doi:10.3389/fnbeh.2011.00044

Jovanovic, T., Norrholm, S. D., Blanding, N. Q., Davis, M., Duncan, E., Bradley, B., and Ressler, K. J. (2010). Impaired fear inhibition is a biomarker of PTSD but not depression. Depress. Anxiety 27, 244-251.

Kay, T., Harrington, D. E., Adams, R., Anderson, T., and Berrol, S. (1993). Definition of mild traumatic brain injury. J. Head Trauma Rehabil. 8, 86-88.

Kolb, B. (1992). "Mechanisms underlying recovery from cortical injury: reflections on progress and directions for the future," in
Recovery from Brain Damage, eds F. D. Rose and D. A. Johnson (New York: Springer-Verlag), 169-186.

Koliatsos, V. E., Cernak, I., Xu, L., Song, Y., Savonenko, A., Crain, B. J., Eberhart, C. G., Frangakis, C. E., Melnikova, T., Kim, H., and Lee, D. (2011). A mouse model of blast injury to brain: initial pathological, neuropathological, and behavioral characterization. J. Neuropathol. Exp. Neurol. 70, 399-416.

Kuehn, R., Simard, P. F., Driscoll, I., Keledjian, K., Ivanova, S., Tosun, C., Williams, A., Bochicchio, G., Gerzanich, V., and Simard, J. M. (2011). Rodent model of direct cranial blast injury. J. Neurotrauma 10 , 2155-2169.

Lew, H. L., Jerger, J. F., Guillory, S. B., and Henry, J. A. (2007). Auditory dysfunction in traumatic brain injury. J. Rehabil. Res. Dev. 44, 921-928.

Lippa, S. M., Pastorek, N. J., Benge, J. F., and Thornton, G. M. (2010). Postconcussive symptoms after blast and nonblast-related mild traumatic brain injuries in Afghanistan and Iraq war veterans. J. Int. Neuropsychol. Soc. 16, 856-866.

Maguen, S., Ren, L., Bosch, J. O., Marmar, C. R., and Seal, K. H. (2010). Gender differences in mental health diagnoses among Iraq and Afghanistan veterans enrolled in veterans affairs health care. Am. J. Public Health 100, 2450-2456.

Management of Post-Traumatic Stress Working Group. (2010). VA/DoD Clinical Practice Guideline for Management of Post-Traumatic Stress. Washington, DC: Department of Veterans Affairs, and Department of Defense.

Margulies, S., and Hicks, R. (2009). Combination therapies for traumatic brain injury: prospective considerations. J. Neurotrauma 26, 925-939.

Masson, F., Maurette, P., Salmi, L. R. Dartigues, J. F., Vecsey, J., Destaillats, J. M., and Erny, P. (1996). Prevalence of impairments 5 years after a head injury, and their relationship with disabilities and outcome. Brain Inj. 10, 487-497.

McFadden, K. L., Healy, K. M., Dettmann, M. L., Kaye, J. T., Ito, T. A., and Hernández, T. D. (2010). Acupressure as a non-pharmacological intervention for traumatic brain injury (TBI). J. Neurotrauma 28 , 21-34.

McLean, A. Jr., Dikmen, S. S., and Temkin, N. R. (1993). Psychosocial recovery after head injury. Arch. Phys. Med. Rehabil. 74, 1041-1046.
National Center for Posttraumatic Stress Disorder. (2010). Report of (VA) Consensus Conference: Recommendations for Treatment of Veterans with Comorbid TBI, Pain, and PTSD. Washington, DC: Department of Veterans Affairs.

Owens, B. D., Kragh, J. F. Jr., Wenke, J. C., Macaitis, J., Wade, C. E., and Holcomb, J. B. (2008). Combat wounds in operation Iraqi Freedom and operation Enduring Freedom. $J$. Trauma 64, 295-299.

Resick, P. A., Monson, C. M., and Chard, K. M. (2010). Cognitive Processing Therapy Veteran/Military Version: Therapist's Manual. Washington, DC: Department of Veterans Affairs.

Rose, F. D., and Johnson, D. A. (1992). "Research on recovery: ends and means," in Recovery from Brain Damage, eds F. D. Rose and D. A. Johnson (New York: Springer-Verlag), 187-198.

Sayeed, I., and Stein, D. G. (2009). Progesterone as a neuroprotective factor in traumatic and ischemic brain injury. Prog. Brain Res. 175, 219-237.

Sayer, N. A., Chiros, C. E., Sigford, B. Scott, S., Clothier, B., Pickett, T., and Lew, H. L. (2008). Characteristics and rehabilitation outcomes among patients with blast and other injuries sustained during the Global War on Terror. Arch. Phys. Med. Rehabil. 89, 163-170.

Skelton, K., Ressler, K. J., Norrholm, S. D., Jovanovic, T., and BradleyDavino, B. (2012). PTSD and gene variants: new pathways and new thinking. Neuropharmacology 62, 628-637.

Soo, C., and Tate, R. (2007). Psychological treatment for anxiety in people with traumatic brain injury. Cochrane Database Syst. Rev. 3 , CD005239.

Tanielian, T., and Jaycox, L. (eds) (2008). Invisible Wounds of War: Psychological and Cognitive Injuries, Their Consequences, and Services to Assist Recovery. Santa Monica, CA: RAND Corporation.

Terrio, H., Brenner, L. A., Ivins, B. J. Cho, J. M., Helmick, K., Schwab, K., Scally, K., Bretthauer, R., and Warden, D. (2009). Traumatic brain injury screening: preliminary findings in a US Army Brigade Combat Team. J. Head Trauma Rehabil. 24 14-23.

Vasterling, J. J., Proctor, S. P., Amoroso, P., Kane, R., Heeren, T., and White, R. F. (2006). Neuropsychological outcomes of army personnel following deployment to the Iraq war. JAMA 296, 519-529.
Warden, D. L., Gordon, B., Mcallister, T. W., Silver, J. M., Barth, J. T., Bruns, J., Drake, A., Gentry, T., Jagoda, A., Katz, D. I., Kraus, J., Labbate, L. A., Ryan, L. M., Sparling, M. B., Walters, B., Whyte, J., Zapata, A. and Zitnay, G. (2006). Guidelines for the pharmacologic treatment of neurobehavioral sequelae of traumatic brain injury. J. Neurotrauma 23, 1468-1501.

Wilk, J. E., Thomas, J. L., Mcgurk, D. M., Riviere, L. A., Castro, C. A., and Hoge, C. W. (2010). Mild traumatic brain injury (concussion) during combat: lack of association of blast mechanism with persistent postconcussive symptoms. J. Head Trauma Rehabil. 25, 9-14.

Wright, D. W., Kellermann, A. L. Hertzberg, V. S., Clark, P. L., Frankel, M., Goldstein, F. C., Salomone, J. P. Dent, L. L., Harris, O. A., Ander, D. S., Lowery, D. W., Patel, M. M., Denson, D. D., Gordon, A. B., Wald, M. M., Gupta, S., Hoffman, S. W., and Stein, D. G. (2007). Protect: a randomized clinical trial of progesterone for acute traumatic brain injury. Ann. Emerg. Med. 49, 391-402.

Zafonte, R., Friedewald, W. T., Lee, S. M., Levin, B., Diaz-Arrastia, R., Ansel, B., Eisenberg, H., Timmons, S. D., Temkin, N., Novack, T., Ricker, J., Merchant, R., and Jallo, J. (2009). The citicoline brain injury treatment (COBRIT) trial: design and methods. J. Neurotrauma 26 , 2207-2216.

Conflict of Interest Statement: The authors declare that the research was conducted in the absence of any commercial or financial relationships that could be construed as a potential conflict of interest.

Received: 30 September 2011; accepted: 16 February 2012; published online: 07 March 2012.

Citation: Brenner LA, Bahraini N and Hernández TD (2012) Perspectives on creating clinically relevant blast models for mild traumatic brain injury and post traumatic stress disorder symptoms. Front. Neur. 3:31. doi: 10.3389/fneur.2012.00031

This article was submitted to Frontiers in Neurotrauma, a specialty of Frontiers in Neurology.

Copyright () 2012 Brenner, Bahraini and Hernández. This is an open-access article distributed under the terms of the Creative Commons Attribution Non Commercial License, which permits noncommercial use, distribution, and reproduction in other forums, provided the original authors and source are credited. 